\title{
Comparison of the free and total light chain assays in serum and urine samples with immunofixation electrophoresis for detecting monoclonal proteins in patients with monoclonal gammopathy
}

\author{
Maciej Korpysz ${ }^{1 \star}$, Marta Morawska ${ }^{2}$, Agata Burska ${ }^{3}$, Helena Donica ${ }^{1}$
}

\author{
${ }^{1}$ Department of Biochemistry Diagnostics, Medical University of Lublin, 11 Staszica, 20-081 Lublin, Poland \\ ${ }^{2}$ The Clinic of Hematooncology and Bone Marrow Transplantation, SPSK 1, Lublin \\ ${ }^{3}$ Leeds Institute of Rheumatic and Musculoskeletal Medicine, University of Leeds
}

\begin{tabular}{l}
\hline ARTICLE INFO \\
\hline Received 17 October 2014 \\
Accepted 23 October 2014 \\
\hline
\end{tabular}

Keywords:

free light chains,

total light chains,

monoclonal gammopathy,

multiple myeloma,

immunofixation.

\begin{abstract}
Monoclonal protein (M-protein) is produced by a malignant clone of plasma cells. Detected in serum and/or urine, this typically indicates multiple myeloma (MM) or other monoclonal gammopathy (MG). In a majority of MM cases, with the production of intact monoclonal immunoglobulin (Ig), malignant plasmocytes and/or B lymphocytes often produce excessive amounts of free light chains (FLCs). Excessive synthesis of FLCs lowers the ability of renal proximal tubules to re-absorb FLCs, which results in abnormally high levels of FLCs in the urine (Bence Jones protein, BJP). In laboratory practice, there are tests available for the quantitative measurement of only FLCs $\kappa$ and $\lambda$ or for total light chains (TLCs). These tests measure both free forms and bound in the (Ig) molecules forms as light chains that are evident in the serum and in urine. The purpose of this study was to evaluate the FLCs and TLCs approaches in screening serum and urine samples of patients with MM, doing so in comparison to the results of immunofixation (IFE) assessment. A second purpose was to assess the suitability of the collected material for obtaining the most reliable results. The results of serum FLCs (sFLCs) assays suggest that this approach is of the highest reliability and diagnostic usefulness in the detection of MG with excess production of FLCs, in comparison to other available tests. In our work, when $\kappa$ band light chains were detected in serum IFE (sIFE), 91\% patients had their FLCs concentrations beyond the reference range, whereas $89 \%$ patients had increased $\lambda$ FLCs when $\lambda$ band light chains were detected in sIFE. We also found abnormal sFLC $\kappa / \lambda$ ratios in $86.4 \%$ and $88.9 \%$ of all subject patients who had $\kappa$ or $\lambda$ band light chains detected in their sIFE, respectively.
\end{abstract}

\section{INTRODUCTION}

A characteristic feature of multiple myeloma (MM) and other monoclonal gammopathies (MG) is the presence of monoclonal proteins (M-proteins) in the serum and/or urine. This is produced by malignant clones of plasma cells. The synthesized immunoglobulins (Igs) are most often of IgG and IgA class, while in the light chain disease (LCD), M-protein is composed of the light chains (LC) alone [14]. A repertoire of tests is available to detect and quantify the

\footnotetext{
Corresponding author

e-mail: m.korpysz@gmail.com

phone: 815322803
}

M-protein in patients with suspected MG. Standard methods include serum and urine protein electrophoresis (SPE and UPE), and, to determine the type of M-protein in serum and urine samples, immunofixation (sIFE and UIFE) is employed [2]. Approximately $67 \%$ of patients with an M-component in their serum further excrete Bence Jones proteins (BJP) in their urine. This is due to significant overproduction of free light chains (FLCs) by malignant clones of B cells, especially in patients with LCD, as well as in the majority of MM cases with complete monoclonal Ig. Excessive synthesis and release of FLCs overwhelms the absorptive capacity of proximal tubules, hence the appearance BJP in the urine [1]. 
In recent years, a new diagnostic test was developed for serum or urine measurement of immunoglobulin FLCs. In 1982, Sølling [27] separated FLCs from LC bonded to Ig molecules and found FLCs in $86 \%$ of MM patients doing so by using column chromatography. This has been confirmed by many later studies $[7,25]$. The FLC test is particularly useful in the diagnosis and monitoring of treatment of MM patients, amyloidosis [17], LCD [12] and smouldering myeloma [6].

Currently, the most commonly used methods for FLCs ( $\kappa$ and $\lambda$ ) determination are nephelometric and turbidimetric techniques which use a specific antibody to recognize the hidden antigenic determinant of LC (usually covered by heavy chains in the intact Ig molecule). These tests do not recognize $\kappa$ and $\lambda$ bound to heavy chains $[2,3,10,12,15]$. In laboratory practice, however, there are tests available for the quantitative measurement of total light chains ( $\kappa$ and $\lambda$ ) (TLCs) which measure both free forms and forms bound to the Ig molecules, together in serum (sTLCs) and in urine (uTLCs).

The purpose of this study was to evaluate the FLCs and TLCs determination approaches in screening serum and urine samples of patients with MM, doing so in comparison with the results of IFE. A second purpose was to assess the suitability of material to obtain the most reliable results.

\section{MATERIAL AND METHODS}

Patients. The study included 44 patients (21 women and 23 men) diagnosed with MG, and treated in The Clinic of Hematooncology and Bone Marrow Transplantation, SPSK-1, Lublin, Poland. The MM of intact monoclonal Ig was detected in 28 patients, LCD in 12 patients and oligoclonal bands were detected in 4 patients.

At the time of diagnosis, additional parameters, such as the type and concentration of monoclonal protein, calcium, creatinine, and beta2-microglobulin were determined in serum.

Ethics approval was obtained from the Bioethics Committee at Medical University of Lublin, Poland, and patients provided informed consent for the use of their samples for this study.

Material. Blood serum samples were taken at fasting, from the cubital vein, and withdrawn to test tubes without anticoagulants, while urine samples were collected into sterile universal containers. Both blood and urine samples were centrifuged for $10 \mathrm{~min}$ at 2,000rpm. Samples were either tested immediately or stored at -20 until analysis. The set of tests performed included: electrophoresis (SPE), immunofixation electrophoresis (IFE), measurement of free light chains (FLCs) and total light chains (TLCs) of kappa $(\kappa)$ and lambda $(\lambda)$. The testing was carried out in The Department of Biochemical Diagnostics of the Medical University of Lublin. All measurements were performed as part of the routine set-up at laboratory of SPSK-1 in Lublin.

Laboratory analysis. SPE was performed on agarose gels (Sebia, France) adjusted to the automatic Hydrasys (Sebia, France) system. Separated fractions were stained with amido black, and electrophoregrams were read by a scanner using PHORESIS 4.1x software. Electrophoresis allowed the detection of M-protein and M-pik quantification. Beyond this, sIFE was done by way of the Hydragel 4 IF kit (Sebia, France) on Hydrasys. This test uses antiserums against heavy chains (anti-IgG, anti-IgM, anti-IgA) and antiserums against LC (anti- $\kappa$ and anti- $\lambda$ ), such an approach recognizes both FLCs and LC bound to intact Igs. This type of sIFE testing allows identification of type of the monoclonal Ig present in the serum.

In addition, uIFE was done by Hydragel 4 Bence Jones (Sebia, France) on Hydrasys. This test uses five antiserums: a trivalent cocktail consisting of antibodies directed against heavy chains $(\mathrm{G}, \mathrm{A}, \mathrm{M})$; two antisera detecting both free and bound $\kappa$ and $\lambda$ LC; and two antisera detecting only the free $\kappa$ and $\lambda$ LC. The UIFE analysis allows identification of type of the monoclonal protein in the urine. Both sIFE and UIFE were performed according to the manufacturer's recommendations.

Serum and urine FLCs (sFLCs and uFLCs) were analyzed by FREELITE ${ }^{\mathrm{TM}}$ kit (The Binding Site, UK), using a nephelometric analyzer Dade Behring BN II (Siemens, Germany). The FREELITE ${ }^{\mathrm{TM}}$ reagent kit is designed for quantitative determination of FLC. The antibodies used were epitopespecific, accessible solely in $\kappa$ and $\lambda$ FLC. This guarantees detection of FLC alone. The reference values for the investigated light chains are: FLC $\kappa 3.3-19.4 \mathrm{mg} / \mathrm{L}$; FLC $\lambda$ 5.71-26.3 mg/L; FLC $\kappa / \lambda$ 0.26-1.65 in serum, and FLC $\kappa 1.35-24.2 \mathrm{mg} / \mathrm{L}$; FLC $\lambda$ 0.24-6.66 mg/L; FLC $\kappa / \lambda 2.04-$ 10.37 in urine.

Serum and urine TLCs (sTLCs and uTLCs) were analyzed by N Antisera to Human Immunoglobulin/L-chains kit, using a nephelometric analyzer Dade Behring BN II (Siemens, Germany). This kit is designed for the quantitative determination of bound and free $\kappa$ and $\lambda$ types of human $\mathrm{Ig} \mathrm{LC}$ in human serum and urine. The reference values for the investigated light chains are: TLC $\kappa$ 1.7-3.7 g/L; TLC $\lambda$ 0.9-2.1 $\mathrm{g} / \mathrm{L} ;$ TLC $\kappa / \lambda$ 1.35-2.65 in serum, and TLC $\kappa<9$ $\mathrm{mg} / \mathrm{L}$; TLC $\lambda<7 \mathrm{mg} / \mathrm{L}$ in urine. A reference range of $\kappa / \lambda$ ratio of 0.75-4.5 in urine was reported [5].

Statistical analysis. The results were analyzed with the use of STATISTICA StatSoft 10.0 and MedCalc 10.2.0. The Tables present percentages of cases with FLCs and TLCs concentrations above the upper, within and below the lower reference values in urine and serum samples, depending on the type of LC in IFE. Additionally, Spearman's test was used to assess correlations between $\kappa$ and $\lambda$ FLCs and TLCs in serum and urine. To verify diagnostic utility of the FLCs and TLCs measurements, ROC curves and analysis of area under curve (AUC) were applied. The ROC curves were plotted with respect to the positive results in IFE. Statistical significance was assumed at $\mathrm{p}<0.05$.

\section{RESULTS}

Based on the SPE and SIFE, monoclonal protein was detected in 44 patients diagnosed with MM. The types of monoclonal protein identified in our study group were as follows: $\operatorname{IgG} \kappa(\mathrm{n}=13), \operatorname{IgA} \kappa(\mathrm{n}=5), \operatorname{IgG} \lambda(\mathrm{n}=6), \operatorname{IgA} \lambda(\mathrm{n}=4)$ and oligoclonal pattern $(n=4)$. Among 12 patients diagnosed with LCD, $n=4$ were of $\kappa$, while $n=8$ of $\lambda$ LC. The patients' characteristics are shown in Table 1. 
Table 1. Patient demographics and laboratory characteristics

\begin{tabular}{|l|c|}
\hline \multicolumn{1}{|c|}{ Parameter } & $\begin{array}{c}\text { MM patients } \\
\mathrm{n}=44\end{array}$ \\
\hline Gender (M/F) & $21 / 23$ \\
\hline Median age (range) & $65(42-85)$ \\
\hline Ig-subtype*: IgG/IgA/BJ/oligoclonal & $19 / 9 / 12 / 4$ \\
\hline Light chain-subtype: $\mathrm{k} / \mathrm{\lambda} /$ both* & $22 / 18 / 4$ \\
\hline Hb $<10 \mathrm{~g} / \mathrm{dl}$ & $21(48 \%)$ \\
\hline Creatinin $>2 \mathrm{mg} / \mathrm{dl}$ & $10(22 \%)$ \\
\hline Albumin $<3.5 \mathrm{~g} / \mathrm{dl}$ & $20(45 \%)$ \\
\hline Beta2-M $>3 \mathrm{mg} / \mathrm{l}$ & $40(91 \%)$ \\
\hline
\end{tabular}

*Immunfixation results; M-male; F-female; Ig-immunoglobulin; $\mathrm{Hb}$ hemoglobin, Beta2-M-beta2-microglobulin

In the group of patients positive for $\kappa$ free LC, or associated with the heavy chain in sIFE, $91 \%$ patients had FLCs $\kappa$ concentration above the upper limit of the reference range. Of the samples where $\kappa$ chain was detected in UIFE, the concentration of UFLCs $\kappa$ exceeded the upper limit of the reference values in $82 \%$ of the cases (Table 2 ).

Table 2. Percentage of cases with FLCs $\kappa$ concentrations in urine and serum, depending on the type of LC found in the serum and urine IFE, respectively

\begin{tabular}{|c|c|c|c|c|c|c|c|}
\hline \multirow{2}{*}{$\begin{array}{c}\text { Type } \\
\text { of light } \\
\text { chain in } \\
\text { sIFE }\end{array}$} & \multicolumn{3}{|c|}{$\mathrm{sFLC} \mathrm{k}(\mathrm{mg} / \mathrm{L})$} & \multirow{2}{*}{\begin{tabular}{|c|} 
Type \\
of light \\
chain in \\
UIFE
\end{tabular}} & \multicolumn{3}{|c|}{$\mathrm{uFLC} \kappa(\mathrm{mg} / \mathrm{L})$} \\
\hline & $<3.3$ & $3.3-19.4$ & $>19.4$ & & $<1.35$ & $\begin{array}{c}1.35- \\
24.2\end{array}$ & $>24.2$ \\
\hline $\mathrm{K}$ & $\begin{array}{c}0 \\
(0 \%)\end{array}$ & $\begin{array}{c}2 \\
(9 \%)\end{array}$ & $\begin{array}{c}20 \\
(91 \%)\end{array}$ & $\mathrm{K}$ & $\begin{array}{c}1 \\
(5 \%)\end{array}$ & $\begin{array}{c}3 \\
(13 \%)\end{array}$ & $\begin{array}{c}18 \\
(82 \%)\end{array}$ \\
\hline$\lambda$ & $\begin{array}{c}4 \\
(22.2 \%)\end{array}$ & $\begin{array}{c}8 \\
(44.4 \%)\end{array}$ & $\begin{array}{c}6 \\
(33.4 \%)\end{array}$ & $\lambda$ & $\begin{array}{c}0 \\
(0 \%)\end{array}$ & $\begin{array}{c}7 \\
(39 \%)\end{array}$ & $\begin{array}{c}11 \\
(61 \%)\end{array}$ \\
\hline$\kappa+\lambda$ & $\begin{array}{c}0 \\
(0 \%)\end{array}$ & $\begin{array}{c}0 \\
(0 \%)\end{array}$ & $\begin{array}{c}4 \\
(100 \%)\end{array}$ & $\lambda$ & $\begin{array}{c}0 \\
(0 \%)\end{array}$ & $\begin{array}{c}1 \\
(25 \%)\end{array}$ & $\begin{array}{c}3 \\
(75 \%)\end{array}$ \\
\hline
\end{tabular}

Of note, sTLCs $\kappa$ levels were elevated only in $45.5 \%$ of patients with LC $\kappa$ in sIFE analysis. Discordant results were found in $54.5 \%$ of the samples, where, despite visible $\kappa$ band evident in SIFE, $27.25 \%$ of the TLCs results fell within the normal range, and $27.25 \%$ were below the lower reference value. In contrast, results of the analysis of urine samples presented higher concordance, and UTLCs $\kappa$ concentrations were elevated in $72.3 \%$ of patients with visible $\kappa$ band in uIFE. Moreover, TLCs $\kappa$ were detected in $66.6 \%$ cases where uIFE was positive for LC $\lambda$ (Table 3.)

Table 3. Percentage of cases with TLCs $\kappa$ concentrations in serum and urine, depending on the type of $\mathrm{LC}$ found in the serum and urine IFE, respectively

\begin{tabular}{|c|c|c|c|c|c|c|}
\hline \multirow{2}{*}{\begin{tabular}{|c|} 
Type \\
of light \\
chain in \\
sIFE
\end{tabular}} & \multicolumn{3}{|c|}{ sTLC k $(\mathrm{g} / \mathrm{L})$} & \multirow{2}{*}{\begin{tabular}{|c|} 
Type \\
of light \\
chain in \\
uIFE
\end{tabular}} & \multicolumn{2}{|c|}{ uTLC K (mg/L) } \\
\hline & $<1.7$ & $1.7-3.7$ & $>3.7$ & & $\leq 9$ & $>9$ \\
\hline $\mathrm{K}$ & $\begin{array}{c}6 \\
(27.25 \%)\end{array}$ & $\begin{array}{c}6 \\
(27.25 \%)\end{array}$ & $\begin{array}{c}10 \\
(45.5 \%)\end{array}$ & $\mathrm{k}$ & $\begin{array}{c}6 \\
(27.7 \%)\end{array}$ & $\begin{array}{c}16 \\
(72.3 \%)\end{array}$ \\
\hline$\lambda$ & $\begin{array}{c}13 \\
(72 \%)\end{array}$ & $\begin{array}{c}4 \\
(22 \%)\end{array}$ & $\begin{array}{c}1 \\
(6 \%)\end{array}$ & $\lambda$ & $\begin{array}{c}6 \\
(33.4 \%)\end{array}$ & $\begin{array}{c}12 \\
(66.6 \%)\end{array}$ \\
\hline$\kappa+\lambda$ & $\begin{array}{c}0 \\
(0 \%)\end{array}$ & $\begin{array}{c}0 \\
(0 \%)\end{array}$ & $\begin{array}{c}4 \\
(100 \%)\end{array}$ & $\kappa+\lambda$ & $\begin{array}{c}0 \\
(0 \%)\end{array}$ & $\begin{array}{c}4 \\
(100 \%)\end{array}$ \\
\hline
\end{tabular}

In the next stage of the analysis, we verified the diagnostic usefulness of the $\kappa$ FLCs and TLCs in serum and urine. The ROC curves were plotted with respect to the positive results in IFE (Figure 1).

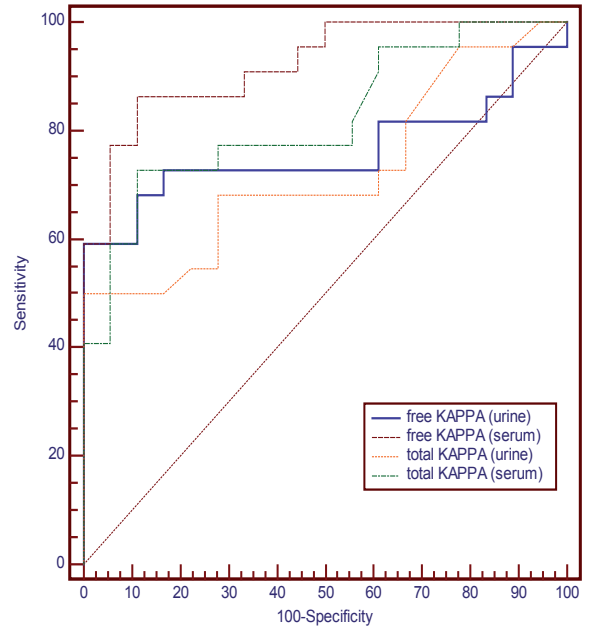

Figure 1. ROC curves of $\kappa$ FLCs and TLCs in serum and urine, against the presence of $\kappa$ band in IFE

Comparative analysis of four ROC curves for four $\kappa$ tests showed the largest AUC for the determination of $\kappa$ FLCs in serum (AUC $=0.922$ ). AUCs for the determination of $\kappa$ FLCs in urine and TLCs in the serum and urine were $0.763,0.821$, and 0.725 , respectively. Additionally, AUC for $\kappa$ FLCs in the serum was significantly higher $(p<0.05)$ from the AUC, for $\kappa$ FLCs in the urine (0.922 vs 0.763$)$ and $\kappa$ TLCs in the urine ( 0.922 vs 0.725$)$.

In the presence of $\lambda$ band in SIFE and UIFE, elevated concentrations of $\lambda$ FLCs, both in serum and urine were found in $89 \%$ and $83.3 \%$ of all cases, respectively (Table 4 ).

In $38.9 \%$ patients positive for $\lambda$ band in SIFE, TLCs $\lambda$ levels were above the upper limit of the reference values. In a similar number of cases, results fell within the reference range, and in $22.2 \%$ of all cases, these were below the lower reference value. On the other hand, $66.7 \%$ of the samples showing $\lambda$ band in UIFE, had elevated concentrations of uTLCs $\lambda$ (Table 5).

The ROC curves for $\lambda$ FLCs and TLCs in serum and urine are presented in Figure 2.

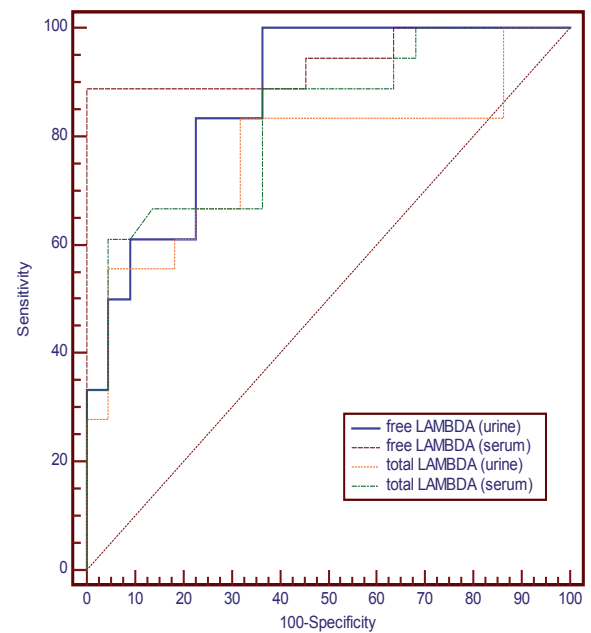

Figure 2. ROC curves of $\lambda$ FLCs and TLCs in serum and urine, against the presence of $\lambda$ band in IFE 
Table 4. Percentages of $\lambda$ FLCs concentrations in serum and urine, depending on the type of LC found in the serum and urine IFE, respectively

\begin{tabular}{|c|c|c|c|c|c|c|c|}
\hline \multirow{2}{*}{$\begin{array}{c}\text { Type } \\
\text { of light } \\
\text { chain in } \\
\text { sIFE } \\
\end{array}$} & \multicolumn{3}{|c|}{$\operatorname{sFLC} \lambda(\mathrm{mg} / \mathrm{L})$} & \multirow{2}{*}{\begin{tabular}{|c|} 
Type \\
of light \\
chain in \\
uIFE
\end{tabular}} & \multicolumn{3}{|c|}{$\mathrm{uFLC} \lambda(\mathrm{mg} / \mathrm{L})$} \\
\hline & $<5.71$ & $\begin{array}{c}5.71- \\
26.3\end{array}$ & $>26.3$ & & $<0.24$ & $\begin{array}{l}0.24- \\
6.66\end{array}$ & $>6.66$ \\
\hline к & $\begin{array}{c}8 \\
(36.4 \%)\end{array}$ & $\begin{array}{c}11 \\
(50 \%)\end{array}$ & $\begin{array}{c}3 \\
(13.6 \%)\end{array}$ & K & $\begin{array}{c}0 \\
(0 \%)\end{array}$ & $\begin{array}{c}14 \\
(63.6 \%)\end{array}$ & $\begin{array}{c}8 \\
(36.4 \%)\end{array}$ \\
\hline$\lambda$ & $\begin{array}{c}0 \\
(0 \%)\end{array}$ & $\begin{array}{c}2 \\
(11 \%)\end{array}$ & $\begin{array}{c}16 \\
(89 \%)\end{array}$ & $\lambda$ & $\begin{array}{c}0 \\
(0 \%)\end{array}$ & $\begin{array}{c}3 \\
(16.7 \%)\end{array}$ & $\begin{array}{c}15 \\
(83.3 \%)\end{array}$ \\
\hline$\kappa+\lambda$ & $\begin{array}{c}0 \\
(0 \%)\end{array}$ & $\begin{array}{c}2 \\
(50 \%)\end{array}$ & $2(50 \%)$ & $\kappa+\lambda$ & $\begin{array}{c}1 \\
(25 \%)\end{array}$ & $\begin{array}{c}2 \\
(50 \%)\end{array}$ & $\begin{array}{c}1 \\
(25 \%)\end{array}$ \\
\hline
\end{tabular}

Table 5. Percentages of $\lambda$ TLCs concentrations in serum and urine, depending on the type of LC found in the serum and urine IFE, respectively

\begin{tabular}{|c|c|c|c|c|c|c|}
\hline \multirow{2}{*}{\begin{tabular}{|c|} 
Type \\
of light \\
chain in \\
sIFE \\
\end{tabular}} & \multicolumn{3}{|c|}{$\operatorname{sTLC} \lambda(\mathrm{g} / \mathrm{L})$} & \multirow{2}{*}{$\begin{array}{c}\text { Type } \\
\text { of light } \\
\text { chain in } \\
\text { uIFE }\end{array}$} & \multicolumn{2}{|c|}{ UTLC $\lambda(\mathrm{mg} / \mathrm{L})$} \\
\hline & $<0.9$ & $0.9-2.1$ & $>2.1$ & & $\leq 7$ & $>7$ \\
\hline $\mathrm{k}$ & $\begin{array}{c}14 \\
(63.7 \%)\end{array}$ & $\begin{array}{c}7 \\
(31.8 \%)\end{array}$ & $\begin{array}{c}1 \\
(4.5 \%)\end{array}$ & $\mathrm{k}$ & $\begin{array}{c}15 \\
(68.2 \%)\end{array}$ & $\begin{array}{c}7 \\
(31.8 \%)\end{array}$ \\
\hline$\lambda$ & $\begin{array}{c}4 \\
(22.2 \%)\end{array}$ & $\begin{array}{c}7 \\
(38.9 \%)\end{array}$ & $\begin{array}{c}7 \\
(38.9 \%)\end{array}$ & $\lambda$ & $\begin{array}{c}6 \\
(33.3 \%)\end{array}$ & $\begin{array}{c}12 \\
(66.7 \%)\end{array}$ \\
\hline$\kappa+\lambda$ & $\begin{array}{c}0 \\
(0 \%)\end{array}$ & $\begin{array}{c}2 \\
(50 \%)\end{array}$ & $\begin{array}{c}2 \\
(50 \%)\end{array}$ & $\mathrm{k}+\lambda$ & $\begin{array}{c}0 \\
(0 \%)\end{array}$ & $\begin{array}{c}4 \\
(100 \%)\end{array}$ \\
\hline
\end{tabular}

Comparative analysis of four ROC curves showed the largest AUC for FLCs $\lambda$ in serum $(\mathrm{AUC}=0.94)$. AUCs for the determination of FLCs in urine, and TLCs $\lambda$ in the serum and urine were $0.871,0.827$, and 0.768 , respectively. The AUC for serum $\lambda$ FLCs measurements was significantly higher $(\mathrm{p}<0.05)$ than the AUC for $\lambda$ TLCs in the urine $(0.94$ vs. 0.768$)$, and in serum (0.94 vs. 0.827$)$.

The results of FLC $\kappa / \lambda$ and TLC $\kappa / \lambda$ ratios in serum and urine samples, in relation to the findings in IFE, are shown in Table 6 and 7. In the group of patients who presented $\kappa$ chains in sIFE and uIFE, $86.4 \%$ and $54.5 \%$ had abnormal (above the upper limit of the reference range) FLC $\kappa / \lambda$ ratios, respectively. Of note, the FLC $\kappa / \lambda$ ratio in serum was, in only $13.6 \%$ of all cases, within the normal range in the group when $\kappa$ band was detected in the IFE. In contrast, when the $\lambda$ band was detected in IFE, the FLC $\kappa / \lambda$ ratios in serum and urine were below the lower limit of the reference values in $88.9 \%$ and $77.8 \%$ of all patients, respectively (Table 6).

Table 6. Percentages of FLC $\kappa / \lambda$ ratios in serum and urine, depending on the type of LC found in the sIFE and UIFE, respectively

\begin{tabular}{|c|c|c|c|c|c|c|c|}
\hline \multirow{2}{*}{\begin{tabular}{|c|} 
Type \\
of light \\
chain in \\
sIFE
\end{tabular}} & \multicolumn{3}{|c|}{$\mathrm{sFLC} k / \lambda$} & \multirow{2}{*}{\begin{tabular}{|c|} 
Type \\
of light \\
chain in \\
uIFE
\end{tabular}} & \multicolumn{3}{|c|}{ uFLC $k / \lambda$} \\
\hline & $<0.26$ & $\begin{array}{c}0.26- \\
1.65\end{array}$ & $>1.65$ & & $<2.04$ & $\begin{array}{l}2.04- \\
10.37\end{array}$ & $>10.37$ \\
\hline $\mathrm{K}$ & $0(0 \%)$ & $\begin{array}{c}3 \\
(13.6 \%) \\
\end{array}$ & $\begin{array}{c}19 \\
(86.4 \%) \\
\end{array}$ & $\mathrm{k}$ & $2(9.1 \%)$ & $\begin{array}{c}8 \\
(36.4 \%) \\
\end{array}$ & $\begin{array}{c}12 \\
(54.5 \%)\end{array}$ \\
\hline$\lambda$ & $\begin{array}{c}16 \\
(88.9 \%)\end{array}$ & $\begin{array}{c}2 \\
(11.1 \%)\end{array}$ & $0(0 \%)$ & $\lambda$ & $\begin{array}{c}14 \\
(77.8 \%)\end{array}$ & $\begin{array}{c}4 \\
(22.2 \%)\end{array}$ & $0(0 \%)$ \\
\hline $\begin{array}{c}k \\
+\lambda\end{array}$ & $0(0 \%)$ & $2(50 \%)$ & $2(50 \%)$ & $\kappa+\lambda$ & $0(0 \%)$ & $2(50 \%)$ & $2(50 \%)$ \\
\hline
\end{tabular}

In the group of patients with $\kappa$ chain in sIFE, $54.5 \%$ had an elevated TLC ratio in their serum samples, while the results of their urine sample analysis showed an elevated ratio of $\kappa / \lambda$ only in $50 \%$ of all patients. When $\lambda$ band was detected in SIFE, the TLC $\kappa / \lambda$ ratios in serum and urine were below the lower limit of the reference values in $55.5 \%$ and $50 \%$ of all patients, respectively (Table 7 ).

Finally, we found a negative relationship between sFLCs $\kappa$ and $\lambda(\mathrm{r}=-0.49, \mathrm{p}<0.01)$, but no significant correlations either for uFLCs, or sTLCs and uTLCs.
Table 7. Percentages of TLC $\kappa / \lambda$ ratios in serum and urine, depending on the type of LC found in the sIFE and uIFE, respectively

\begin{tabular}{|c|c|c|c|c|c|c|c|}
\hline \multirow{2}{*}{\begin{tabular}{|c|} 
Type \\
of light \\
chain in \\
sIFE
\end{tabular}} & \multicolumn{3}{|c|}{ sTLC $k / \lambda$} & \multirow{2}{*}{$\begin{array}{c}\text { Type } \\
\text { of light } \\
\text { chain in } \\
\text { uIFE }\end{array}$} & \multicolumn{3}{|c|}{ uTLC $\mathrm{k} / \lambda$} \\
\hline & $<1.35$ & $\begin{array}{l}1.35- \\
2.65\end{array}$ & $>2.65$ & & $<0.75$ & $0.75-4.5$ & $>4.5$ \\
\hline $\mathrm{k}$ & $\begin{array}{c}0 \\
(0 \%)\end{array}$ & $\begin{array}{c}10 \\
(45.5 \%)\end{array}$ & $\begin{array}{c}12 \\
(54.5 \%)\end{array}$ & K & $\begin{array}{c}0 \\
(0 \%)\end{array}$ & $\begin{array}{c}11 \\
(50 \%)\end{array}$ & $\begin{array}{c}11 \\
(50 \%)\end{array}$ \\
\hline$\lambda$ & $\begin{array}{c}10 \\
(55.5 \%)\end{array}$ & $\begin{array}{c}8 \\
(44.5 \%)\end{array}$ & $\begin{array}{c}0 \\
(0 \%)\end{array}$ & $\lambda$ & $\begin{array}{c}9 \\
(50 \%)\end{array}$ & $\begin{array}{c}8 \\
(44.5 \%)\end{array}$ & $\begin{array}{c}1 \\
(5.5 \%)\end{array}$ \\
\hline$\kappa+\lambda$ & $\begin{array}{c}0 \\
(0 \%)\end{array}$ & $\begin{array}{c}2 \\
(50 \%)\end{array}$ & $\begin{array}{c}2 \\
(50 \%)\end{array}$ & $k+\lambda$ & $\begin{array}{c}3 \\
(75 \%)\end{array}$ & $\begin{array}{c}1 \\
(25 \%)\end{array}$ & $\begin{array}{c}0 \\
(0 \%)\end{array}$ \\
\hline
\end{tabular}

\section{DISCUSSION}

This study aimed at comparing FLCs and TLCs assays of serum and urine samples, doing so with reference to IFE results. Additionally, we wanted to find out which biological material would produce more reliable results. SPE and/or UPE, along with IFE, are routine diagnostic tests if MG is suspected [2]. These tests allow the detection of M-protein, and they define its type in terms of the structure being of either light, heavy chain or both. Recently, both serum and urine immunonephelometry or immunoturbidimetry of FLCs have been commonly used in laboratory practice to diagnose and monitor the effectiveness of treatment of patients with MG [2,10-12,29], although TLCs assays are available as well. TLCs assay allows the quantitative measurement of $\kappa$ and $\lambda$ LCs, both that which is free and that which is bound to the Ig molecule. In our study, we determined both FLCs and TLCs levels in serum and urine samples.

Our results found distinctly increased concentrations of $\kappa$ or $\lambda$ FLC, depending on the type of chain detected in sIFE. This was also evident in our previous study [16]. Our current study revealed that when $\kappa$ band was detected on SIFE, $91 \%$ of all patients had their sFLCs concentrations beyond the reference range, while $89 \%$ of all patients had increased $\lambda$ FLC when $\lambda$ band was detected on sIFE. These results let us assert that excessive production of FLCs was observed in the majority of patients who had intact monoclonal Ig detected in sIFE. However, a few patients had normal sFLCs concentration despite $\kappa$ or $\lambda$ band being detected on SIFE ( $9 \%$ and $11 \%$ respectively). This suggests the absence of excess production of FLCs in these patients.

Occasionally, when M-protein is detected, FLC concentration can remain within the normal range due to other reasons. This can come about by way of an altered sequence of aminoacids in Ig LC, as this can reorganize epitopes of FLC, and that, in turn, can cause no reaction with anti-light free chain (anti-LFC) serum. In such cases, the results of SPE and/or IFE should be considered as well [28].

Jaskowski et al. [9] found abnormal concentrations of $\kappa$ FLCs in $72.9 \%$ of all patients who had $\kappa$ band detected on SIFE. Moreover, when $\lambda$ band was seen on sIFE, $91.4 \%$ of all patients had concentrations of $\lambda$ FLCs above the normal reference range. Such a finding complies with our results.

In healthy people, FLCs are filtered in the glomeruli and metabolized in the proximal tubules. Only trace amounts of FLCs are secreted with urine when in normal physiological condition (1-10 mg/24h) [3,20]. In patients suffering from $\mathrm{MG}$, the ability of the proximal tubules to reabsorb FLCs is excessive, and, thus, the high amounts of FLCs produced by 
tumor plasmocytes enter into the urine $[1,4]$. Nowrousian et al. [22] carried out an interesting study which aimed at establishing the threshold of sFLC, which, when exceeded, leads to BJP appearance in the urine. They found that the median $\kappa$ FLC in serum that is associated with monoclonal FLCs being present in the urine was $113 \mathrm{mg} / \mathrm{L}$, and 40 $\mathrm{mg} / \mathrm{L}$, if no FLCs were determined in a urine sample. In the patients who had BJP of $\lambda$ type, and in the group who had no M-protein in their urine, the median of serum monoclonal $\lambda$ FLCs was $278 \mathrm{mg} / \mathrm{L}$ and $44 \mathrm{mg} / \mathrm{L}$, respectively. The simultaneous elevation in $\lambda$ sFLCs and the presence of BJP type $\lambda$ in a urine sample is likely to be associated with dimerization of $\lambda$ FLCs. Dimerization of $\lambda$ chains results in its decreased glomerular filtration when compared to monomers typical for $\kappa$ chains [3].

In our work, we compared the results of uIFE with $\mathrm{uFLC}$, and found that, depending on the type of LC present on UIFE, uFLCs were increased in $82 \%$ and $83.3 \%$ of all patients in our study. This revealed a substantial overproduction of free chains and their subsequent filtration into the urine. However, the results were slightly lower in comparison to the results obtained in serum tests. The fact that the amount of FLCs entering urine largely depends on kidney function, points to the advantage of utilizing sFLC assays. In the course of MG, especially in case of LCD, FLCs are detected predominantly in serum in the first stage of the disease. In the second stage, these can be detected in both serum and urine samples, and in the third stage only in urine samples. Therefore, increased sFLCs is an indicator of the active disease process in plasmocyte dyscrasias [4]. Furthermore, the ROC curves that we generated confirm the better diagnostic utility of sFLCs assay. Therein, AUCs for serum $\kappa$ and $\lambda$ FLC were the largest, 0.922 and 0.94 respectively.

Our study partially confirmed the results reported by van Hoeven et al. [30]. They compared the sensitivity of various methods for FLCs detection, and these authors found a significantly higher sensitivity for SFLCs assays than for urine tests. Furthermore, they found that the sensitivity of an UFLCs assay for the samples that tested positively on uIFE, was significantly higher than for UPE alone - 89\% vs. 52\%, respectively. Nowrousian et al. [22] also compared uFLCs sensitivity with UIFE, in patients with MM. They found that the samples that were positive for light chains in UIFE had median uFLCs concentrations of $448 \mathrm{mg} / \mathrm{L}$ for $\kappa$ and $313 \mathrm{mg} / \mathrm{L}$ for $\lambda$. What is more, the samples that produced negative uIFE results had median UFLCs $\kappa$ and $\lambda$ concentrations of $23 \mathrm{mg} / \mathrm{L}$ and $9 \mathrm{mg} / \mathrm{L}$, respectively. Other authors' results were similar [31]; they concluded that uIFE is a more reliable test for detecting $\mathrm{MG}$, when compared to UFLCs. However, the comparison of UIFE and uFLCs in detecting urine BJP by Viedma et al. [31] demonstrated that despite correct identification by FLC assay, the high background noise of polyclonal FLCs makes interpretation of FLC $\kappa / \lambda$ ratios more difficult in urine samples. Hence, the uIFE test was more accurate in detecting M-protein. This, we confirmed in our study. Of note, other authors believe that immunochemical assays measuring FLCs and UIFE complement each other $[18,19]$.

FLC $\kappa / \lambda$ ratio was another parameter referred to the IFE results. This ratio provides better diagnostic utility than does separate measurements of FLCs. Singhal et al. [24] found abnormal values of that parameter in $66 \%$ of all patients who tested positively to sIFE. This also complies with our results. In our work, we found abnormal FLC $\kappa / \lambda$ ratios in $86.4 \%$ and $88.9 \%$ of all patients who had $\kappa$ or $\lambda$ band detected on SIFE, respectively. The FLC $\kappa / \lambda$ ratio is mainly affected by the dominant production of one type of LC by clonally proliferated plasmocytes, and the suppressed production of normal LC of the other type. With regard to this, an analysis of correlations has revealed an inverse relationship between $\kappa$ and $\lambda$ sFLCs $(r=-0.49$, $p<0.01)$, which suggests the possible application of sFLCs assay to monitor the changes involved, as well as to assess the level of uninvolved FLCs that come about in the course of MG. Of note, our study found no such correlations between uFLCs or sTLCs and uTLCs.

The values of FLC ratios obtained in our study also confirm the better diagnostic utility of FLCs measured in serum rather than in urine. We found abnormal FLC $\kappa / \lambda$ ratio urine results in $54.5 \%$ and $77.8 \%$ of all patients, depending on the type of $\kappa$ or $\lambda$ LC found in UIFE. Dispenzieri et al. [7] and Katzmann et al. [13] also examined a large group of patients with MM, and found abnormal sFLCs $\kappa / \lambda$ ratios (in $96 \%$ and $96.8 \%$ of all patients, respectively). In addition, it should be mentioned that the ranges for FLCs and $\kappa / \lambda$ ratios in serum samples derived from healthy individuals are considerably narrower than for urine samples, and this contributes to more accurate and reliable results, and to higher diagnostic value. Moreover, an uFLCs assay is still affected by issues related to urine collection and storage. FLC tend to precipitate in urine more than in serum samples due to lower $\mathrm{pH}$ [3]. Siegel et al. [23] suggested, therefore, that because of such factors, UPE is highly susceptible to error. The analysis of 623 urine samples of a 24-hour collection found fluctuating results of UPE. Of these, $19 \%$ gave a false increase in M-protein, compared to results in serum which were more stable.

Herzog and Hoffman et al. [8] analyzed urine and serum FLCs and TLCs in a group of 33 patients who had detected BJP. In this study, the authors further investigated a group of five patients with LCD and 28 patients with intact Ig accompanied by the secretion of FLC into urine. They suggested that abnormal sFLC $\kappa / \lambda$ ratios are more sensitive than $\mathrm{uFLC} \kappa / \lambda$ ratios and that the uTLC $\kappa / \lambda$ ratio was of little diagnostic usefulness.

In our study, abnormal uTLC $\kappa / \lambda$ ratio was noted only in $50 \%$ of all patients, and sTLC $\kappa / \lambda$ ratios were abnormal only in $54.5 \%$ and $55.5 \%$ of all patients, depending on the type of LC detected on sIFE. Those results were substantially worse than those of an FLC assay. Moreover, AUCs for serum and urine TLCs prove to be of lesser diagnostic value than an FLCs assay. This confirms the limited application of this test as a diagnostic tool for MM.

Snyder et al. [26] also assessed the usefulness of uFLCs and/or uTLCs as supplementary tests to UPE in monitoring patients who had M-protein detected in their urine. Their investigation was carried out on 336 urine samples that tested positively in UIFE. The results found a $80 \%$ and $70 \%$ test sensitivity for UFLCs and uTLCs, respectively. However, the diagnostic sensitivity of measurements for 
urine samples which had no M-protein detected on electrophoresis was substantially lower. It was concluded that uFLCs and uTLCs assays are not useful as complementary tests to electrophoresis.

The results by Mariën et al. [21] also confirmed the little usefulness of serum $\kappa$ and $\lambda$ TLCs measurements. The researchers found abnormal FLC $\kappa / \lambda$ ratio in all 16 examined patients with LCD. However, TLC $\kappa / \lambda$ ratios were abnormal in only 5 patients, and one $\lambda$ patient was misclassified as $\kappa$. The authors concluded that TLC measurement is of little diagnostic value for clinical practice, which further supports our results.

\section{CONCLUSION}

The results of sFLCs assays suggest highest reliability and diagnostic utility in the detection of $\mathrm{MG}$ with excessive production of sFLCs, in comparison to other accessible tests. Furthermore, an sFLC assay should be complemented by calculating FLC $\kappa / \lambda$ ratios, as these best reflect the monoclonal character of gammopathy, and indicate high compatibility with sIFE tests. Additionally, sFLC assay allows monitoring of the changes in involved and uninvolved FLCs, which can be especially useful for the evaluation of response to treatment.

\section{REFERENCES}

1. Abraham R.S. et al.: Correlation of serum immunoglobulin free light chain quantification with urinary Bence Jones protein in light chain myeloma. Clin. Chem., 48, 655, 2002.

2. Bradwell A.R. et al.: Highly sensitive, automated immunoassay for immunoglobulin free light chains in serum and urine. Clin. Chem., 47, 673, 2001.

3. Bradwell A.R.: Serum Free Light Chain Analysis. 6th ed. Bradwell 2010.

4. Bradwell A.R. et al.: Serum test for assessment of patients with Bence Jones myeloma. Lancet. 361, 489, 2003.

5. Brouwer J., Otting-van de Ruit M., Busking-van der Lely H.: Estimation of free light chains of immunoglobulins by enzyme immunoassay. Clin. Chim. Acta., 150, 267, 1985.

6. Dispenzieri A. et al.: Immunoglobulin free light chain ratio is an independent risk factor for progression of smoldering (asymptomatic) multiple myeloma. Blood. 111, 785, 2008.

7. Dispenzieri A. et al.: Appraisal of immunoglobulin free light chain as a marker of response. Blood. 111, 4908, 2008.

8. Herzog W., Hoffman W.: Detection of free kappa and lambda light chains in serum and urine in patients with monoclonal gammopathy. Blood 102, 5190a, 2003.

9. Jaskowski T.D., Litwin C.M., Hill H.R.: Detection of kappa and lambda light chain monoclonal proteins in human serum: automated immunoassay versus immunofixation electrophoresis. Clin. Vaccine. Immunol., 13, 277, 2006.

10. Jenner E: Serum free light chains in clinical laboratory diagnostics. Clin. Chim. Acta 427, 15, 2014.
11. Katzmann J.A., Abraham R.S., Dispenzieri A.: Diagnostic performance of quantitative kappa and lambda free light chain assays in clinical practice. Clin. Chem., 51, 878, 2005.

12. Katzmann J.A., Clark R.J., Abraham R.S.: Serum reference intervals and diagnostic ranges for free kappa and free lambda immunoglobulin light chains: relative sensitivity for detection of monoclonal light chains. Clin. Chem., 48, 1437, 2002.

13. Katzmann J.A., Kyle R.A., Benson J.: Screening panels for detection of monoclonal gammopathies. Clin. Chem., 55, 1517, 2009.

14. Kendziorek A., Bobilewicz D.M.: Badania laboratoryjne w różnych stadiach rozwoju gammapatii monoklonalnych. In Vitro Explorer, 1, 3, 2007.

15. Korpysz M. et al.: Concentrations of free light chains determined by nephelometry and turbidimetry. Curr. Iss. Pharm. Med. Sci. 25, 434, 2012.

16. Korpysz M., Malecha-Jędraszek A., Donica H.: Blood serum free light chain concentration vs. Immunofixation results in patients with monoclonal gammopathy. Curr. Iss. Pharm. Med. Sci., 25, 430, 2012.

17. Lachmann H.J. et al.: Outcome in systemic AL amyloidosis in relation to changes in concentration of circulating free immunoglobulin light chains following chemotherapy. Br. J. Haematol., 122, 78, 2003.

18. Levinson S.S.: Complementarily of urine analysis and serum free light chain assay for assessing response treatment response: illustrated by three case examples. Clin. Chim. Acta., 412, 2206, 2011.

19. Levinson S.S.: Urine immunofixation electrophoresis remains important and is complementary to serum free light chain. Clin. Chem. Lab. Med., 49, 1801, 2011.

20. Levinson S.S., Keren D.F.: Free light chains of immunoglobulins: clinical laboratory analysis. Clin. Chem., 40, 1869, 1994.

21. Mariën G. et al.: Detection of monoclonal proteins in sera by capillary zone electrophoresis and free light chain measurements. Clin. Chem., 48, 1600, 2002.

22. Nowrousian M.R. et al.: Serum free light chain analysis and urine immunofixation electrophoresis in patients with multiple myeloma. Clin. Cancer Res., 11, 8706, 2005.

23. Siegel D. et al.: Inaccuracies in 24-Hour Urine Testing for Monoclonal Gammopathies. Lab. Med., 40, 341, 2009.

24. Singhal S. et al.: The relationship between the serum free light chain assay and serum immunofixation electrophoresis, and the definition of concordant and discordant free light chain ratios. Blood, 114, 38, 2009.

25. Snozek C.L. et al.: Prognostic value of the serum free light chain ratio in newly diagnosed myeloma: proposed incorporation into the international staging system. Leukemia. 22, 1933, 2008.

26. Snyder M.R. et al.: Quantification of urinary light chains. Clin. Chem., 54, 1744, 2008.

27. Sølling K. et al.: Free light chains of immunoglobulins in serum from patients with leukaemias and multiple myeloma. Scand. J. Haematol., 28, 309, 1982.

28. Tate J.R. et al.: Analytical performance of serum free light-chain assay during monitoring of patients with monoclonal light-chain diseases. Clin. Chim. Acta., 376, 30, 2007.

29. Usnarska-Zubkiewicz L., Hołojda J., Kuliczkowski K.: Serum free light chain (sFLC) - diagnostic and prognostic value in plasma cell dyscrasias. Acta Haematol. Pol., 40, 349, 2009.

30. Van Hoeven K.H. et al.: Serum free light chain assays are more sensitive than urinary tests for free light chain monoclonal paraproteins. Clin. Chem., 55, C30a, 2009.

31. Viedma J.A., Garrigós N., Morales S.: Comparison of the sensitivity of 2 automated immunoassays with immunofixation electrophoresis for detecting urine Bence Jones proteins. Clin. Chem., 51, 1505, 2005. 